\title{
Traction-assisted endoscopic submucosal dissection of a duodenal gastrointestinal stromal tumor
}

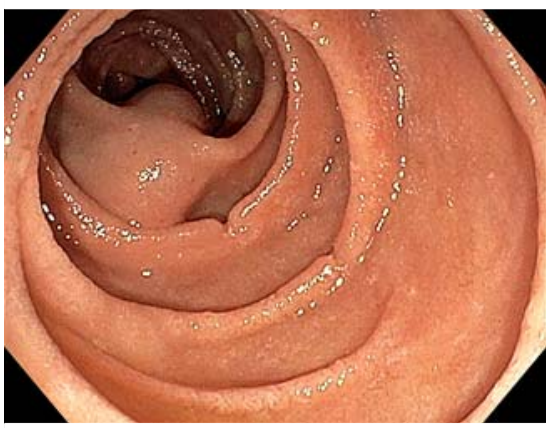

- Fig. 1 Subepithelial lesion in the distal descending duodenum covered by normal mucosa.

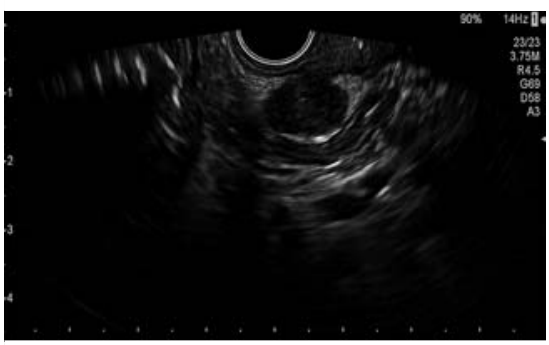

- Fig. 2 Endoscopic ultrasound showing a 15-mm hypoechoic, regular, and homogeneous lesion engaging the muscularis propria.

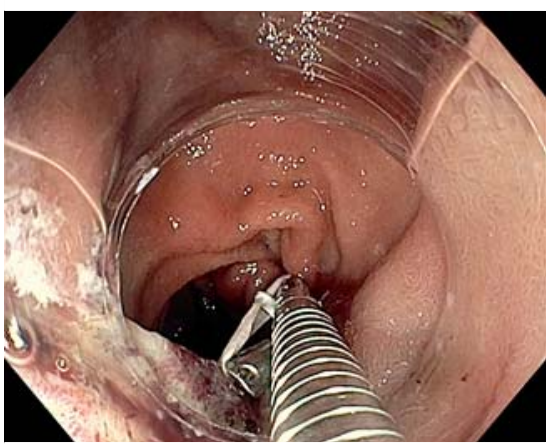

- Fig. 3 Traction system using a dental floss ring and two conventional clips.
A 70-year-old woman with a gastric adenocarcinoma and a subepithelial lesion in the distal descending duodenum ( $\triangleright$ Fig. 1) was referred to us. On endoscopic ultrasound (EUS), a 15-mm hypoechoic, regular, and homogeneous lesion engaging the muscularis propria was observed (> Fig. 2). Histopathology analysis of the fine-needle biopsy showed a gastrointestinal stromal tumor (GIST) with a low proliferative index. After discussion in a multidisciplinary team conference and on patient consent, an endoscopic submucosal dissection (ESD) and gastrectomy were performed in the same session.

In order to facilitate access to the submucosa during ESD, we applied a traction system using a dental floss ring and two clips ( $\triangleright$ Fig.3). This system enabled quick, safe, and complete resection with full control of the dissection plane ( $\triangleright$ Fig.4, $>$ Video 1). The GIST was resected en bloc and the wall defect was fully closed using eight metallic clips and an endoloop ( $>$ Fig.5). There were no adverse events during the procedure. Postoperatively, the patient developed mild abdominal pain, which was easily controlled with painkillers, and oral intake was restarted on day 3. The patient was re-admitted at 2 months owing to fever caused by a retroperitoneal fluid collection that was treated with antibiotherapy and EUS drainage; she remained asymptomatic at the 3-month follow-up. ESD has been increasingly used for the treatment of duodenal epithelial [1] and subepithelial [2,3] lesions. Endoscopic treatment of GISTs is controversial due to the need for complete resection and associated risks. Small series of gastric GIST ESD were described, but only few cases of GIST ESDs were reported [4]

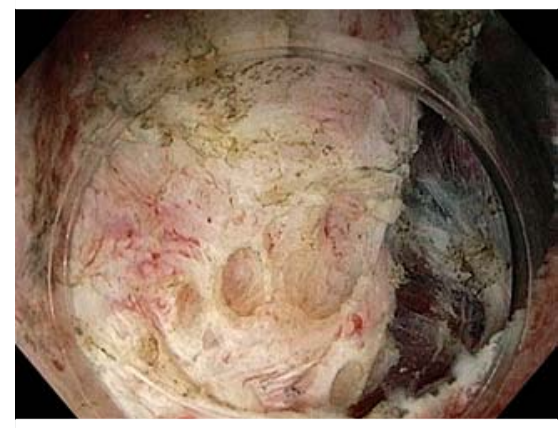

Fig. 4 Traction system enabling full control of the dissection plane.

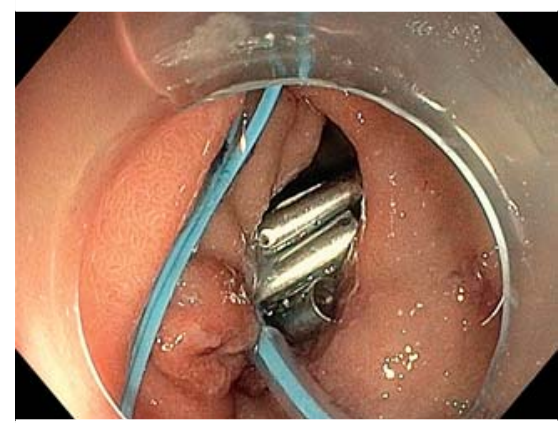

Fig. 5 Closure of the wall defect after tumor resection using eight metallic clips and an endoloop.

and none with this technique. Several traction devices may be used for ESD [5], but this GIST was located in the distal duodenum, precluding the use of most of them. This case also highlights the need for long and close follow-up of these patients.

Endoscopy_UCTN_Code_CCL_1AB_2AZ_3AB

\section{Competing interests}

The authors declare that they have no conflict of interest. 


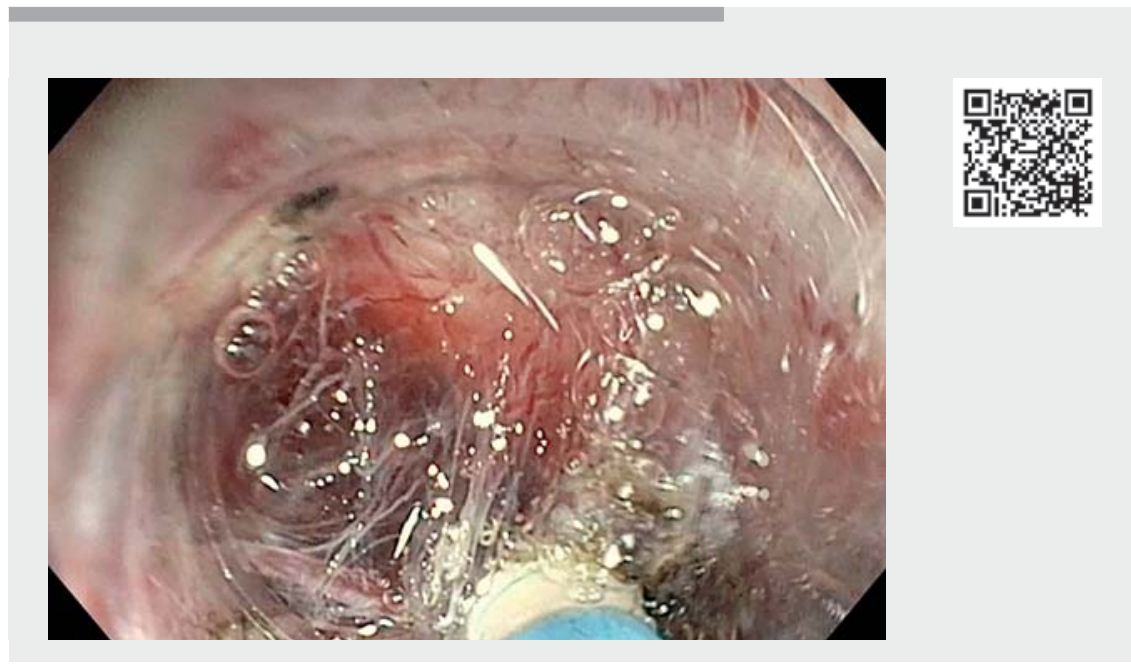

$\checkmark$ Video 1 Endoscopic submucosal dissection of a gastrointestinal stromal tumor using a traction system.
The authors

\section{Francisco Baldaque-Silva ${ }^{1}$, Naining Wang ${ }^{2}$,} Ioannis Rouvelas ${ }^{3}$, Masami Omae ${ }^{1}$

1 Division of Medicine, Department of Upper Gastrointestinal Diseases, Karolinska University Hospital and Karolinska Institute, Stockholm, Sweden

2 Department of Pathology, Karolinska University Hospital and Karolinska Institute, Stockholm, Sweden

3 Division of Surgery, Department of Clinical Science, Intervention and Technology (CLINTEC), Karolinska Institute, Stockholm, Sweden

\section{Corresponding author}

\section{Francisco Baldaque-Silva, MD}

Department of Upper Gastrointestinal Diseases, Karolinska University Hospital, Huddinge, 14186 Stockholm, Sweden fbaldaquesilva@gmail.com
Bibliography

Endoscopy 2022; 54: E318-E319

DOI 10.1055/a-1527-7600

ISSN 0013-726X

published online 9.7.2021

(C) 2021. Thieme. All rights reserved.

Georg Thieme Verlag KG, Rüdigerstraße 14, 70469 Stuttgart, Germany

\section{ENDOSCOPY E-VIDEOS}

https://eref.thieme.de/e-videos

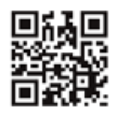

Endoscopy E-Videos is an open access online section, reporting on interesting cases and new techniques in gastroenterological endoscopy. All papers include a high quality video and all contributions are freely accessible online. Processing charges apply (currently EUR 375), discounts and wavers acc. to HINARI are available.

This section has its own submission website at https://mc.manuscriptcentral.com/e-videos Endoscopic mucosal resection and endoscopic submucosal dissection in the treatment of sporadic nonampullary duodenal adenomatous polyps. World J Gastrointest Endosc 2015; 7: 720-727

[2] Oung B, Walter T, Hervieu V et al. Nonampullary duodenal subepithelial neuroendocrine tumor removed RO by endoscopic submucosal dissection with double clips and rubber band traction. VideoGIE 2019; 4: 570-573

[3] Tashima T, Nonaka K, Kurumi H et al. Successful traction-assisted endoscopic submucosal dissection using dental floss and a clip for a huge superficial nonampullary duodenal epithelial tumor with severe fibrosis (with video). JGH Open 2018; 3: 179-181

[4] Granata A, Amata M, Ligresti D et al. Underwater full-thickness resection of a duodenal bulb gastrointestinal stromal tumor with OverStitch defect repair. Endoscopy 2019; 51: E207-E208

[5] Baldaque-Silva F, Vilas-Boas F, Velosa M et al. Endoscopic submucosal dissection of gastric lesions using the "yo-yo technique". Endoscopy 2013; 45: 218-221 